\title{
Altered balance between Th17 and Th1 cells at mucosal sites predicts AIDS progression in simian immunodeficiency virus-infected macaques
}

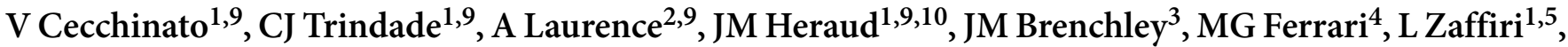 \\ E Tryniszewska $^{1,6}$, WP Tsai ${ }^{1}$, M Vaccari $^{1}$, R Washington Parks ${ }^{1}$, D Venzon $^{7}$, DC Douek $^{8}$, JJ O’Shea ${ }^{2}$ and \\ G Franchini $^{1}$
}

Loss of CD4 ${ }^{+} \mathrm{T}$ cells in the gut is necessary but not sufficient to cause AIDS in animal models, raising the possibility that a differential loss of CD4 ${ }^{+}$T-cell subtypes may be important. We found that CD4 ${ }^{+} \mathrm{T}$ cells that produce interleukin (IL)-17, a recently identified lineage of effector $\mathrm{CD}^{+}{ }^{+} \mathrm{T}$-helper cells, are infected by $\mathrm{SIV}_{\text {mac251 }}$ in vitro and in vivo, and are found at lower frequency at mucosal and systemic sites within a few weeks from infection. In highly viremic animals, Th1 cells predominates over Th17 T cells and the frequency of Th17 cells at mucosal sites is negatively correlated with plasma virus level. Because Th17 cells play a central role in innate and adaptive immune response to extracellular bacteria, our finding may explain the chronic enteropathy in human immunodeficiency virus (HIV) infection. Thus, therapeutic approaches that reconstitute an adequate balance between Th1 and Th17 may be beneficial in the treatment of HIV infection.

\section{INTRODUCTION}

The mucosal immune system, including the gut, is an early target of human immunodeficiency virus (HIV)/simian immunodeficiency virus (SIV) infection. Hallmarks of HIV-1 infection are immune activation, $\mathrm{CD} 4^{+} \mathrm{T}$-cell loss, and susceptibility to opportunistic infection..$^{1,2}$ Whether $\mathrm{CD} 4^{+} \mathrm{T}$-cell loss is caused by direct HIV killing of $\mathrm{CD} 4^{+} \mathrm{T}$ cells or by chronic immune activation or both is still a source of debate. ${ }^{3}$

Mucosal surfaces constitute the largest immunological barriers against microorganisms in the body. In both pathogenic SIV macaque models and in HIV-1 infection of humans, loss of $\mathrm{CD} 4{ }^{+} \mathrm{CCR}^{+} \mathrm{T}$ cells from all mucosal compartments is observed early in infection ${ }^{4-7}$ and evidence suggests that normal homeostasis of $\mathrm{CD} 4^{+} \mathrm{T}$ cells in these compartments is not reconstituted even when HIV-1-infected individuals are treated by antiretroviral therapy. ${ }^{8}$ While $\mathrm{CD} 4{ }^{+} \mathrm{T}$-cell loss at mucosal sites is likely very important, recent data in a non-pathogenic non-human primate model suggest that depletion of $\mathrm{CD} 4^{+} \mathrm{CCR}^{+} \mathrm{T}$ cells in the gut-associated lymphoid tissue is not sufficient to cause AIDS, ${ }^{9,10}$ raising the possibility that other events, such as the selective loss of $\mathrm{CD} 4^{+} \mathrm{T}$ cells with different effector functions, may be important.

Classically, CD4 ${ }^{+} \mathrm{T}$ cells are composed of Th1 cells that produce interferon- $\gamma($ IFN- $\gamma$ ) and are important for adaptive responses to viruses, intracellular bacteria, and protozoan parasites, and Th2 cells that produce interleukin (IL)-4, IL-5, and IL-13 and direct immune responses to metazoan parasites. Recently, another $\mathrm{CD} 4^{+} \mathrm{T}$-cell subset that produces IL-17, a cytokine important in host defense against extracellular bacteria, was identified (Th17). ${ }^{11-14}$ In mice, IL-17 differentiation is driven by transforming growth factor- $\beta$ and IL- 6 and requires the transcription activator retinoid-related orphan receptor- $\gamma \mathrm{t}$, which in turn activates the expression of IL-17 and the IL-23 receptor (IL-23R). In contrast, in humans,

\footnotetext{
${ }^{1}$ Animal Models and Retroviral Vaccines Section, National Cancer Institute, Bethesda, Maryland, USA. ${ }^{2}$ Molecular Immunology and Inflammation Branch, National Institute of Arthritis, Musculoskeletal and Skin Diseases, Bethesda, Maryland, USA. ${ }^{3}$ mmunopathogenesis Unit, Lab of Molecular Microbiology, National Institute of Allergy and Infectious Diseases, Bethesda, Maryland, USA. ${ }^{4}$ Advanced BioScience Laboratories Inc., Kensington, Maryland, USA. ${ }^{5}$ Department of Infectious and Tropical Diseases, University of La Sapienza, Rome, Italy. ${ }^{6}$ Department of Microbiology Diagnostics, Medical University of Bialystok, Bialystok, Poland. ${ }^{7}$ Biostatistics \& Data Management Section, National Cancer Institute, Bethesda, Maryland, USA. ${ }^{\circ}$ Human Immunology Section, Vaccine Research Center, National Institute of Allergy and Infectious Diseases, Bethesda, Maryland, USA. ${ }^{9}$ These authors contributed equally to this work. ${ }^{10}$ Present address: WHO-National Influenza Laboratory, Institut Pasteur de Madagascar, Antananarivo, Madagascar. Correspondence: G Franchini (franchig@mail.nih.gov) 
Th17 polarization is induced by IL- $1 \beta$ and enhanced by IL- 6 but is suppressed by transforming growth factor- $\beta$ and IL- $12 .{ }^{15}$ Differentiation of Th17 cells is initiated by IL- 6 and requires sequential involvement of both IL-21 and IL-23 pathways. ${ }^{16-19}$ Th17 cells, in addition to IL-17, produce IL-22, a cytokine that induces production of antibacterial defensins.

While the induction and function of Th1 and Th2 cells are well understood, the full spectrum of functions of Th17 cells has not been defined. Th17 cells are important in mucosal immunity to extracellular bacteria. IL-17 induces production of granulocyte-colonystimulating factor and chemokines, which recruit myeloid cells to sites of inflammation. ${ }^{20}$ In this way, IL-17 is thought to be important in the control of extracellular bacterial infection. ${ }^{21}$ For example, recent studies show that IL-17R knockout mice have increased susceptibility to infection with Klebsiella pneumoniae ${ }^{22}$ and mice deficient in the $\mathrm{p} 19$ or $\mathrm{p} 40$ subunit of IL-23 are unable to control Citrobacter rodentium infection. ${ }^{23}$ Furthermore, it has been shown that IL-22 cooperates with IL-17 in the enhancement of the antibacterial response. ${ }^{24}$

Th17 cells are also involved in autoimmune diseases. Recent studies have shown that the polymorphism of the $I L-23 R$ gene has been associated with a lower incidence of inflammatory bowel disease. ${ }^{25}$ Furthermore, it has been shown that psoriatic skin lesions contain IL-23-producing dendritic cells, ${ }^{26}$ and that IL-22 mediates acanthosis through IL-23 induction. ${ }^{23}$ However, it is still unknown whether autoimmunity is mediated by the same type of cells or a different Th17 subtype.

Here, we investigated whether the frequency of Th17 lymphocytes is modified during SIV infection, particularly at mucosal sites. We found that there is a significantly higher number of Th17 cells in the gut than systemic tissues of healthy macaques and that $\operatorname{SIV}_{\text {mac251 }}$ infection results in a significantly higher loss of Th17 than Th1 cells at mucosal sites of SIV-infected macaques. Normal frequencies of Th17 cells are found only in the SIV-infected macaques that could effectively control viral replication. The finding of a significant inverse relationship between the frequency of Th17 cells at mucosal sites and virus levels in plasma suggests a role for Th17 cells in AIDS pathogenesis.

\section{RESULTS}

\section{The frequency of CD4 $+\mathrm{IL}-17^{+} \mathrm{T}$ cells is higher in the gut} than systemic compartments of healthy macaques

Th17 cells are a newly identified subset of $\mathrm{CD} 4^{+}$effector T cells. We characterized their phenotype in naïve rhesus macaques and we found that a discreet specific population of $\mathrm{CD} 4^{+} \mathrm{T}$ cells expressing IL-17 is detected in blood following phorbol 12-myristate 13-acetate (PMA) and ionomycin stimulation (Figure 1a). Most of the Th17 T cells in blood are distinct from Th1 cells that express IFN- $\gamma$ (Figure 1b) and from $\mathrm{CD} 4{ }^{+} \mathrm{CD} 25^{\text {high }}$ regulatory T cells $\left(\mathrm{T}_{\text {reg }}\right)$ as they do not co-stain with the anti-CD25 antibody (Figure 1c).

Next, we studied the distribution of Th1 and Th17 cells in systemic and mucosal tissues collected from 13 healthy uninfected macaques (Table 1). The frequency of CD4 ${ }^{+} \mathrm{IL}-17^{+}$ $\mathrm{T}$ cells in blood, spleen, and lymph nodes was lower than that at mucosal sites (Figure 1d). Analysis of the mean percentage of $\mathrm{CD} 4^{+} \mathrm{IL}-17^{+} \mathrm{T}$ cells in the tissues of the naïve macaques revealed a significant difference in their frequency in systemic and mucosal compartments $(P<0.001)$ (Figure 1e). In contrast, no differences in the frequency of $\mathrm{CD} 4^{+} \mathrm{IFN}-\gamma^{+} \mathrm{T}$ cells were observed between mucosal and systemic compartments (Figure 1f).

\section{CD4 + IL-17+ $\mathrm{T}$ cells are susceptible to SIV infection in vitro and in vivo}

We investigated the susceptibility of Th17 cells to SIV infection in vitro by exposing sorted $\mathrm{CD} 4^{+} \mathrm{T}$ cells from healthy human peripheral blood mononuclear cells (PBMCs) to $\mathrm{SIV}_{\operatorname{mac} 251}$. The p27 Gag protein was detected both in the supernatant of the cell cultures (Figure 2a) and by intracellular staining at day 14 (Figure 2b), showing that the $\mathrm{CD} 4^{+} \mathrm{T}$ cells were productively infected with SIV. The permissiveness of Th17 cells to infection was demonstrated by the detection of cells able to produce simultaneously p 27 Gag and IL-17 by fluorescence-activated cell sorting (Figure 2c). Indeed, our data show that both Th1 and Th17 cells can be infected in vitro by SIV $_{\text {mac251 }}$.

To verify that Th17 cells are also infected in vivo, we obtained mononuclear cells from the spleen of four macaques chronically infected with $\mathrm{SIV}_{\operatorname{mac} 251}$ (Table 1) and sorted CD4 ${ }^{+}$ $\mathrm{CD} 28^{+} \mathrm{CD} 95^{+} \mathrm{T}$ cells producing either IFN- $\gamma$ or IL-17 or neither cytokine (Figure 2d). Analysis of SIV DNA copies in the cellular DNA by quantitative PCR of these $\mathrm{CD}^{+}{ }^{+} \mathrm{T}$-cell populations revealed the presence of viral DNA in both Th1 and Th17 subsets, demonstrating that in vivo Th17 cells are infected (Figure 2e).

\section{Both Th17 and Th1 cells are significantly decreased in blood and lymph nodes but only Th17 cells are decreased at mucosal sites during primary SIV $_{\text {mac251 }}$ infection}

To investigate the fate of $\mathrm{CD}_{4}^{+}$effector T cells following infection with SIV $_{\text {mac251 }}$, we infected nine naïve rhesus macaques by the intrarectal route and enumerated Th17 and Th1 cells in blood, lymph nodes, colon, jejunum, and rectal mucosa. Because in this animal model the peak of viral replication occurs within the first few weeks from exposure to SIV (Figure 3a), we collected all tissues specimens at week 2 from infection (Table 1). We found that the frequency and absolute number of both Th17 and Th1 cells in blood were significantly decreased at 2 weeks from infection (Figure $\mathbf{3 b}, \mathbf{c}$ ). Similarly, in lymph nodes there was a significant decrease in the percentage of both Th17 and Th1 cells (Figure 3d). In contrast, the frequency of Th17 but not Th1 cells was significantly reduced in colon, jejunum, and rectum (Figure 3e-g). If anything, the relative frequency of Th1 cells in the large intestine tended to be higher, suggesting that the decrease in Th17 frequency may be due to an increased recruitment of Th1 cells at these mucosal sites.

\section{Normal frequency of Th17 cells is not reconstituted in systemic and mucosal tissues of chronically infected macaques}

Next, we studied a cohort of 18 macaques that had been infected for more than 8 months with $\mathrm{SIV}_{\operatorname{mac} 251}$ and had CD4 ${ }^{+}$T-cell 


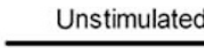

$\alpha-\mathrm{IL}-17$

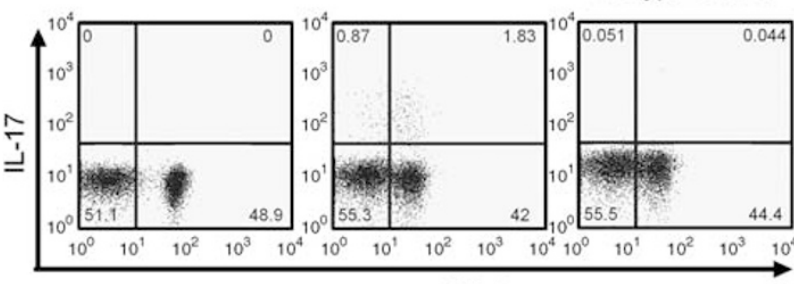

CD4 b

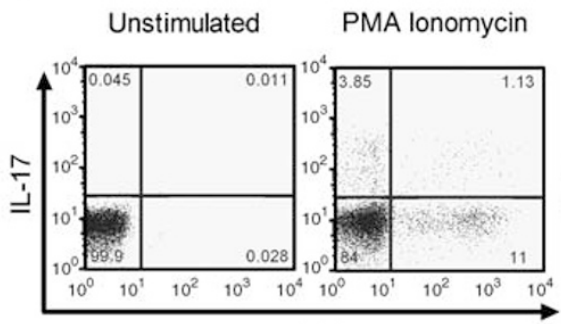

IFN- $\gamma$
C

PMA lonomycin

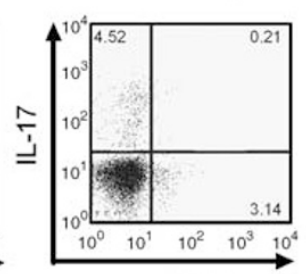

CD25

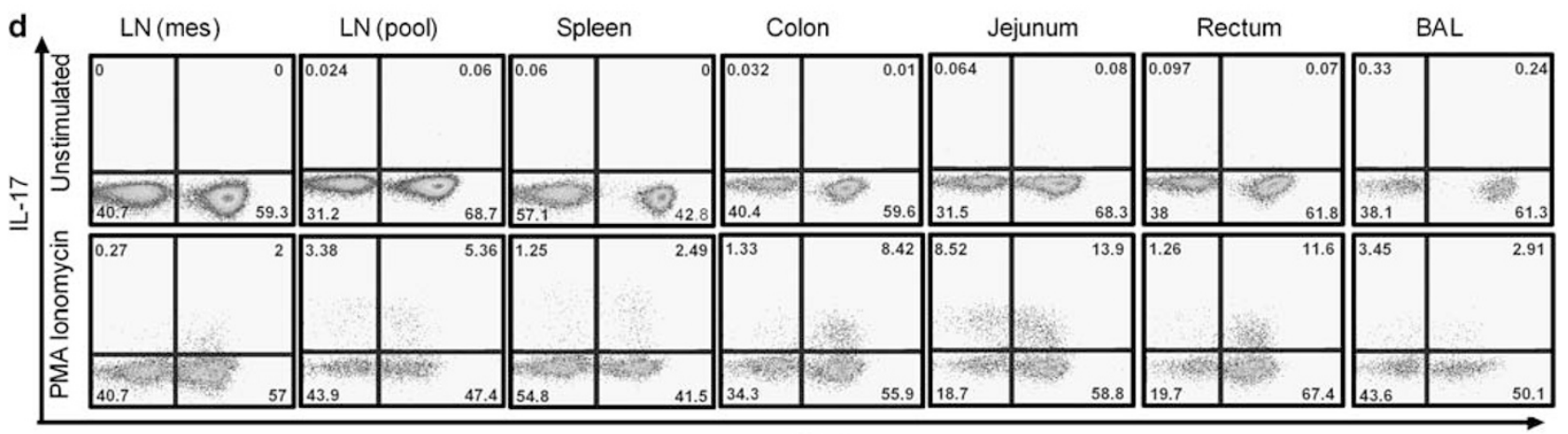

CD4
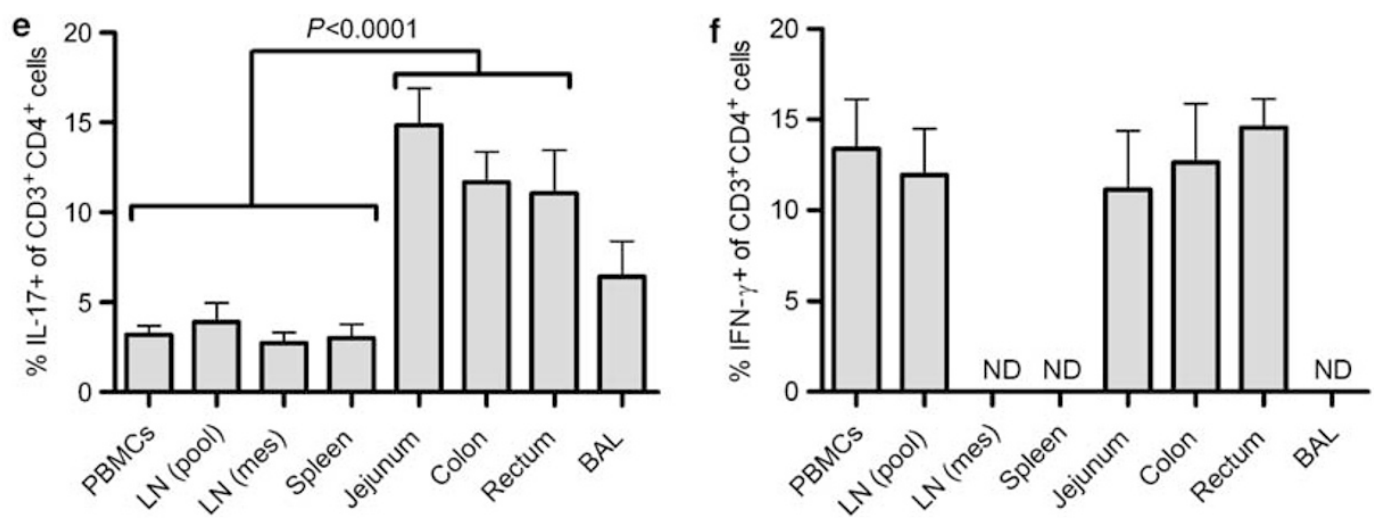

Figure 1 The frequency of $\mathrm{CD}^{+} \mathrm{CD} 4^{+} \mathrm{IL}-17^{+} \mathrm{T}$ cells is significantly higher in mucosal than systemic tissues of healthy macaques. (a) Distinct CD3 ${ }^{+}$ CD4 ${ }^{+} \mathrm{T}$-cell population produces IL-17 only after PMA/ionomycin stimulation. CD3 ${ }^{+} \mathrm{CD} 4^{+} \mathrm{T}$ cells were obtained from blood of a naïve macaque. Left panel: unstimulated; middle and right panels: PMA/ionomycin stimulation, cells stained with anti-IL-17 antibody and isotype control, respectively. (b) PBMCs were obtained from a naïve macaque and stimulated with or without PMA/ionomycin and costained with IL-17 and IFN- $\gamma$. Left panel: unstimulated; right panel: PMA/ionomycin stimulation. (c) Most CD3 ${ }^{+} \mathrm{CD} 4^{+} \mathrm{IL}-17^{+} \mathrm{T}$ cells are $\mathrm{CD} 25^{-}$following stimulation with $\mathrm{PMA}$ and ionomycin. (d) Percentage of CD4 ${ }^{+} \mathrm{IL}-17^{+} \mathrm{T}$ cells in systemic and mucosal sites with or without PMA and ionomycin treatment. (e, f) Mean percentages of CD3 ${ }^{+}$ $\mathrm{CD}^{+} \mathrm{IL}-17^{+} \mathrm{T}$ cells $(\mathbf{e})$ and $\mathrm{CD} 3^{+} \mathrm{CD} 4^{+} \mathrm{IFN}-\gamma^{+} \mathrm{T}$ cells $(\mathbf{f})$ in tissues of healthy macaques. The number of samples analyzed for each tissue varied from four to nine. BAL, bronchial aveolar lavage; IFN, interferon; IL, interleukin; PBMC, peripheral blood mononuclear cell; PMA, phorbol 12-myristate 13-acetate.

counts in blood that ranged between 107 and 651 counts per $\mathrm{mm}^{3}$ and plasma virus levels below or above 50 copies per $\mathrm{ml}$ plasma (Table 1). Similar to our finding in primary SIV $_{\text {mac251 }}$ infection, in chronically infected macaques, the frequency and the absolute number of both Th17 and Th1 effector cells were decreased in blood (Figure 4a,b). Similarly, in lymph nodes the frequency of both $\mathrm{CD} 4^{+}$effector subsets remained significantly lower than that found in naïve macaques (Figure 4c). At mucosal sites, however, only the frequency of Th17 cells was significantly reduced (Figure 4d-f). Analysis of the frequency of Th17 cells in tissues of macaques that had fewer than 50 SIV RNA copies per ml (elite controller macaques) demonstrated no significant differences with that of naïve macaques in jejunum and rectum

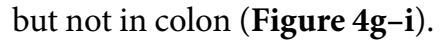

\section{The frequency of Th17 in tissues inversely correlates with virus but not lipopolysaccharide levels in plasma}

Regression analysis using the Spearman rank correlation method was performed using the frequency of Th17 and Th1 cells in all tissues and plasma virus levels. Plasma virus levels were negatively correlated with the percentage of $\mathrm{CD}^{+} \mathrm{IL}^{-17^{+}} \mathrm{T}$ cells in seven of the eight tissues analyzed, and this correlation was 
Table 1 Macaque clinical studies

\begin{tabular}{|c|c|c|c|}
\hline Macaque & $\begin{array}{l}\text { LPS } \\
(\mathrm{pg} / \mathrm{ml})\end{array}$ & $\begin{array}{c}\text { Copies SIV RNA } \\
\text { per ml plasma }\end{array}$ & $\begin{array}{l}\mathrm{CD}^{+}{ }^{+} \mathrm{CD} 4^{+} \\
\mathrm{T} \text { cells }\end{array}$ \\
\hline \multicolumn{4}{|l|}{ Naïve } \\
\hline M653 & 19.5 & 0 & 413 \\
\hline M655 & 9.1 & 0 & 395 \\
\hline M665 & 0 & 0 & 551 \\
\hline M669 & 0 & 0 & 638 \\
\hline M838 & ND & 0 & NA \\
\hline M839 & 5.8 & 0 & 412 \\
\hline M840 & 3.6 & 0 & 523 \\
\hline M841 & 20.0 & 0 & 650 \\
\hline M842 & ND & 0 & NA \\
\hline M999 & ND & 0 & 531 \\
\hline P003 & ND & 0 & 531 \\
\hline P004 & ND & 0 & 691 \\
\hline P005 & ND & 0 & 1053 \\
\hline
\end{tabular}

\section{Chronically infected}

$<50$ copies per $\mathrm{ml}$

M306

M898

M902

M649

M608

$>50$ copies per $\mathrm{ml}$

M398

M310

M215

M222

M595

M563

M379

M645

M552

M395

M564

M601

M647

\begin{tabular}{llll} 
Primary infection & & & \\
M595 & ND & $1.5 \times 10^{8}$ & 782 \\
M640 & ND & $4.8 \times 10^{7}$ & 197 \\
M642 & ND & $3.7 \times 10^{7}$ & 902 \\
M648 & ND & $6.2 \times 10^{7}$ & 496 \\
M649 & ND & $7.4 \times 10^{7}$ & 661 \\
M999 & ND & $3.6 \times 10^{7}$ & 292 \\
P003 & ND & $4.2 \times 10^{7}$ & 227 \\
P004 & ND & $2.2 \times 10^{8}$ & 276 \\
P005 & ND & $2.3 \times 10^{7}$ & 167 \\
\hline
\end{tabular}

LPS, lipopolysaccharide; NA, not applicable; ND, not done. significant for colon $(R=-0.70, P<0.0001)$, rectum $(R=-0.65$, $P=0.0001)$, jejunum $(R=-0.64, P=0.0002)$, $P B M C s(R=-0.57$, $P=0.0033)$, mesenteric lymph nodes $(R=-0.71, P=0.0027)$, pooled lymph nodes $(R=-0.66, P=0.0002)$, and spleen $(R=-0.79, P=0.0002)$ (Figure 5a and data not shown for colon, mesenteric lymph nodes, and spleen). Moreover, the frequency of $\mathrm{CD} 4^{+} \mathrm{IFN}-\gamma^{+} \mathrm{T}$ cells in blood $(R=-0.64, P=0.0002)$, but not in the tissues, was negatively correlated with plasma virus levels (Figure 5b).

Because Th17 cells are important for innate and adaptive responses to extracellular bacteria and because bacterial translocation has been evoked as an underlying mechanism of chronic immune activation observed in HIV and in pathogenic models of SIV, ${ }^{27}$ we investigated whether there was a correlation between the level of lipopolysaccharide (LPS) in plasma and the number of Th17 cells, particularly in the gut. LPS levels varied considerably in plasma of naïve and infected macaques (Table 1) and regression analysis demonstrated no correlation with any of the tissues studied (Figure $\mathbf{5 c}$ and data not shown).

\section{DISCUSSION}

HIV infection of humans is associated with a predominant $\mathrm{CD} 4{ }^{+} \mathrm{T}$-cell loss at mucosal sites and chronic enteropathy. ${ }^{28,29}$ The gastrointestinal tract is continually exposed to food and bacterial antigens and the appropriate balance between regulatory and effector T-cell response maintains its integrity. Within the mouse, there is a complex interplay between inflammatory effector $\mathrm{CD} 4^{+} \mathrm{IL}-17^{+} \mathrm{T}$ cells and regulatory $\mathrm{CD} 4^{+}$ FoxP3 ${ }^{+} \mathrm{T}$ cells. Transforming growth factor- $\beta 1$ itself promotes the differentiation of $\mathrm{CD} 4{ }^{+}$FoxP3 ${ }^{+} \mathrm{T}_{\text {reg }}$, which are involved in the control of autoimmunity. ${ }^{30}$ However, transforming growth factor- $\beta 1$ together with IL- 6 promotes the Th17 lineage ${ }^{31-33}$ by stimulating the expression of the required transcription factor retinoid-related orphan receptor $\gamma \mathrm{t} .{ }^{16}$ Furthermore, the addition of IL- 6 inhibits the generation of $\mathrm{CD}^{+}{ }^{+} \mathrm{FoxP}^{+} \mathrm{T}_{\text {reg }}$

HIV-1 infects $\mathrm{CD}^{+}{ }^{+} \mathrm{FoxP}^{+} \mathrm{T}_{\text {reg }}$ in vitro ${ }^{34}$ and $\mathrm{CD} 4{ }^{+} \mathrm{CD} 25^{+}$ $T$ cells are depleted during SIV infection in the intestinal lamina propria. ${ }^{35}$ However, because phenotype markers such as $\mathrm{CD} 25$ and FoxP3 or gene expression profiles do not distinguish between activated and regulatory $\mathrm{CD} 4{ }^{+} \mathrm{CD} 25^{+} \mathrm{FoxP}^{+} \mathrm{T}$ cells, the role of $\mathrm{T}_{\text {reg }}$ in HIV/SIV pathogenesis remains uncertain. ${ }^{36}$

Here, we demonstrate that in non-human primates the frequency of Th17 cells, but not Th1 cells, is significantly higher at mucosal sites than blood of healthy macaques and that infection with the pathogenic $\operatorname{SIV}_{\mathrm{mac} 251}$ differentially alters the balance between these two $\mathrm{CD}^{+}{ }^{+}$effector subsets at mucosal sites. While in both acute and chronic SIV infection the number of both Th17 and Th1 cells is decreased in blood and lymph nodes, at mucosal sites only the frequency of Th17 cells is decreased during primary infection and it is not restored at normal level in the chronic phase of infection, except in animals able to contain viral replication.

The mechanism related to the apparent loss of Th17 cells remains unclear. We have provided evidence that $\operatorname{SIV}_{\text {mac251 }}$ 

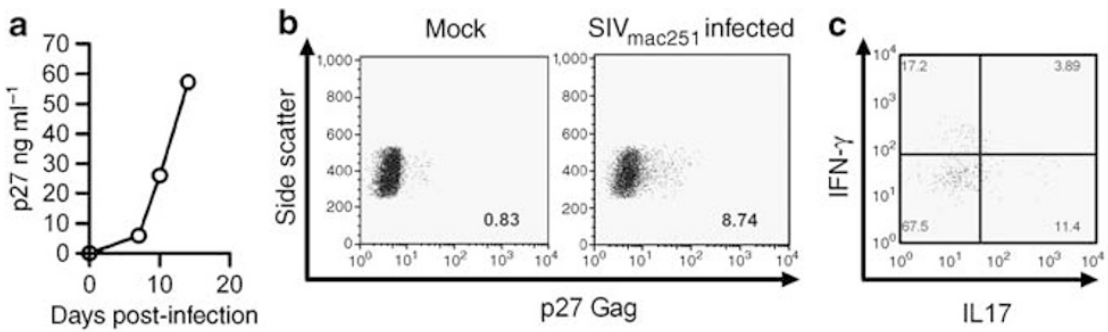

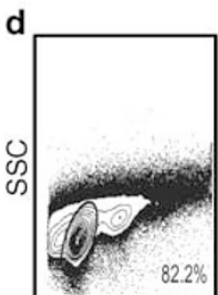

FSC

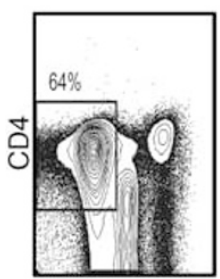

Dump

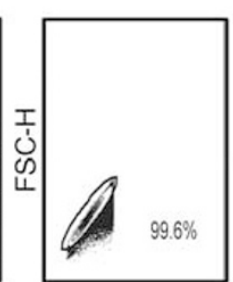

FSC-A

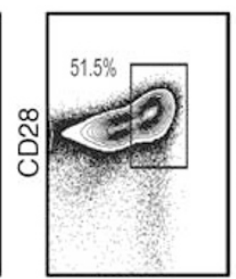

CD95

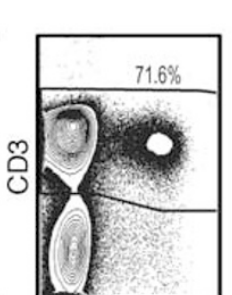

IL-17

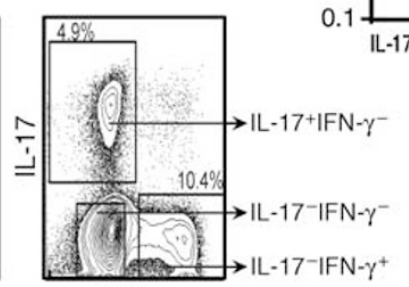

IFN- $\gamma$

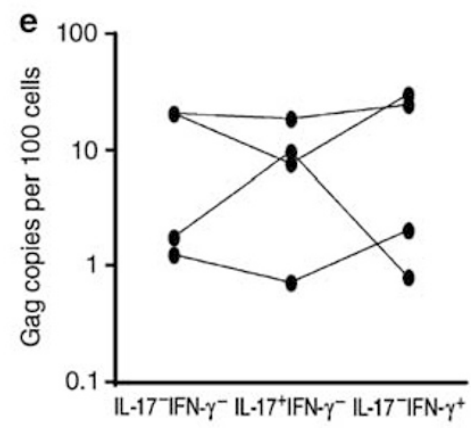

Figure $2 \mathrm{CD}^{+}{ }^{+} \mathrm{IL}-17^{+} \mathrm{T}$ cells are susceptible to SIV $_{\text {mac251 }}$ infection in vitro and in vivo. (a) Viral production measured as p27 Gag in the supernatant of infected cultures by ELISA. (b) Viral production measured by intracellular staining for p27 Gag in infected and mock-infected cultures. (c) IFN- $\gamma$ and IL-17 production within cells that express p27 Gag. (d) Phenotype of sorted CD4+ CD28 ${ }^{+}$CD95 ${ }^{+}$cytokine-producing cells. (e) Quantitation of SIV proviral DNA copies in sorted T-cell populations. IFN, interferon; IL, interleukin; SIV, simian immunodeficiency virus.

infects Th17 cells both in vitro and in vivo; however, the contribution of SIV infection to the apparent loss of Th17 cells needs to be ascertained. It is plausible that Th17 cells are highly activated in the gut because of continuous exposure to bacterial antigens and became a target for the virus.

Th17 cells produce IL-22, IL-17A, or IL-17F that together induce the expression of defensins and other antibacterial products. ${ }^{24}$ IL-22 also induces LPS-binding protein in hepatocytes ${ }^{37}$ and may prevent systemic inflammation provoked by LPS found in blood of HIV-infected individuals. ${ }^{27}$

The loss of Th17 cells may create a vicious cycle in SIV/HIV infection: decreased host defenses to bacteria may favor breaches of the gastrointestinal barrier and result in a further increase in local immune activation and exacerbation of viral replication in the gut. With time, increased local tissue damage could further favor bacterial translocation ${ }^{27}$ and systemic immune activation and lead to the progressive loss of all CD4 ${ }^{+}$T-cell subtypes from all compartments and development of AIDS.

An alternative hypothesis, however, is that there is increased recruitment of Th1 cells at sites of higher viral replication (the gut) with increased local production of INF- $\gamma$, a known inhibitor of Th17 differentiation. ${ }^{38}$

It will be of great importance to demonstrate whether there is a real loss of Th17 cells by examining intact tissues of naïve and infected macaques and to dissect the mechanism(s) underlining the decrease in frequency of Th17 cells, as this information could guide novel therapeutic approaches.

Bacterial infections are frequent in HIV infection. Recurrent bacterial infections are found in children infected with HIV and are associated with a faster decline of CD4 ${ }^{+}$T cells. ${ }^{39} \mathrm{HIV}$ infected individuals have an approximately 10-fold higher risk for bacterial pneumonia ${ }^{40}$ and diarrheal disease occurs with an odd ratio of 10 for AIDS. ${ }^{41}$ In developing countries, cryptococcal meningitis, cryptococcosis, and severe bacterial infection are considered AIDS-defining illnesses, ${ }^{42,43}$ and cryptococcal antigenemia has been well documented. ${ }^{44}$ Interestingly, the introduction of effective antiretroviral therapy has resulted in a decrease in cytomegalovirus-related hospitalization but bacterial infection predominantly increased in the following years. ${ }^{45}$ Candida albicans induces Th17 polarization in vitro, ${ }^{12}$ and oral candidiasis and periodontal disease are frequent in untreated HIV-1-infected individuals. ${ }^{46} \mathrm{HIV}$ patients also have increased susceptibility to Mycobacteria tuberculosis. Interestingly, IL-23 and IL-17 may also be important in optimal responses to M. tuberculosis. ${ }^{47}$ Because of the potential roles of IL-17 in host defense against extracellular bacteria and fungi, it is tempting to speculate that the loss of Th17 cells likely plays a very important role in AIDS pathogenesis.

Our observation that macaques infected with $\mathrm{SIV}_{\text {mac251 }}$ that do not progress to disease (elite controllers) have normal frequency 
a
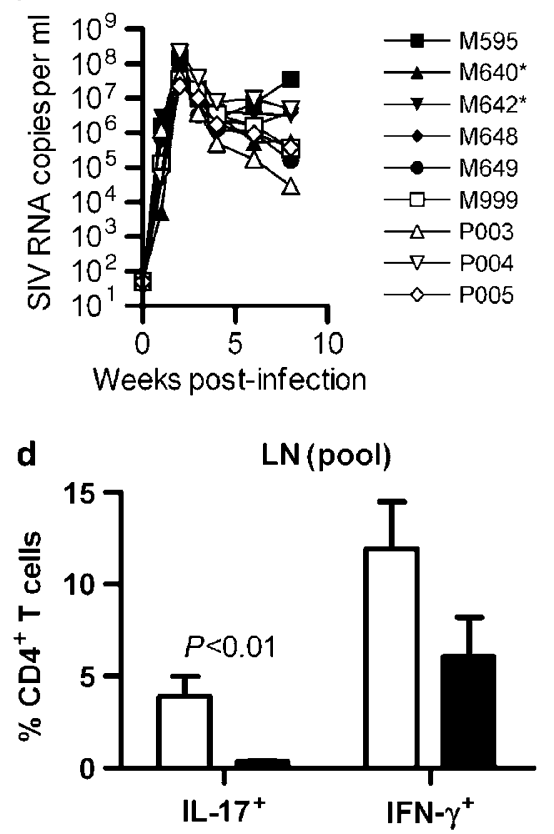

b

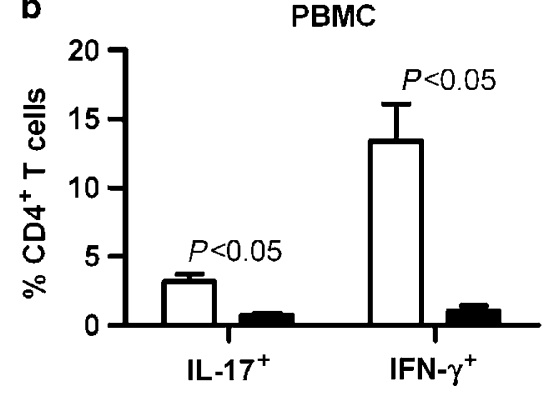

e

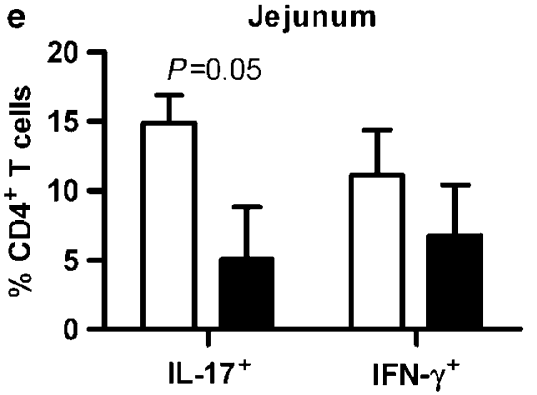

c

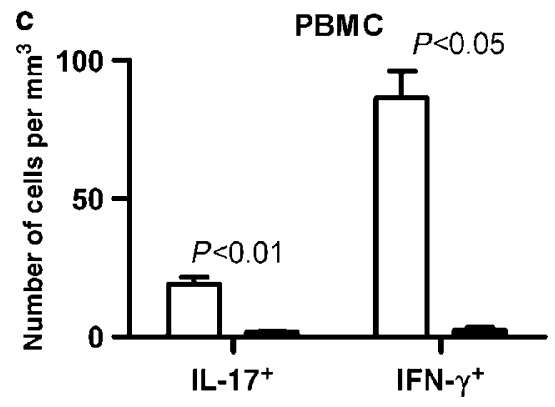

f

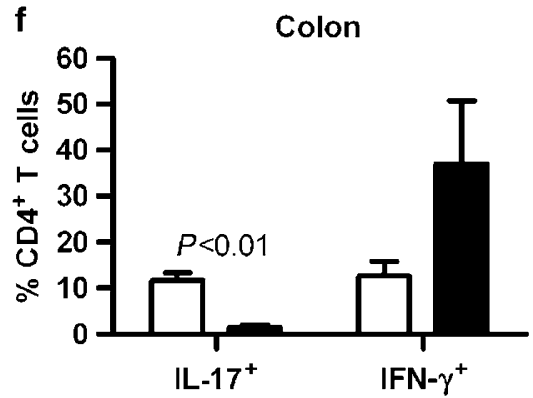

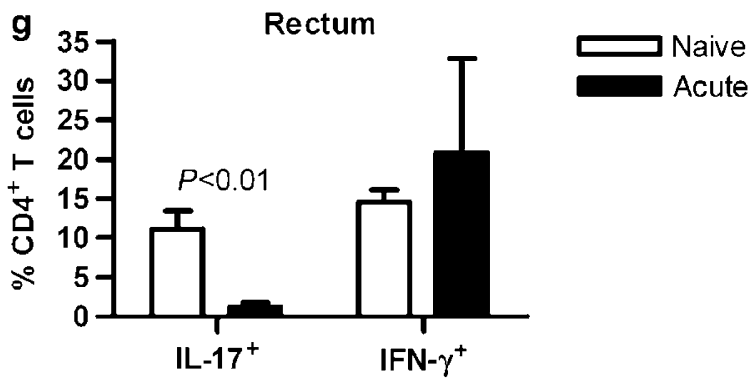

Figure 3 Altered balance between $\mathrm{CD} 4^{+} \mathrm{IL}-17^{+}$and $\mathrm{CD} 4^{+} \mathrm{IFN}-\gamma^{+}$T cells in primary $\mathrm{SIV}_{\text {mac251 }}$ infection. (a) Plasma virus levels in macaques following intrarectal infection with $\mathrm{SIV}_{\text {mac251. }}$ (b, c) Mean percentages (b) and absolute number (c) of CD4 ${ }^{+} \mathrm{IL}-17^{+}$and CD4 ${ }^{+}$IFN- $\gamma^{+} \mathrm{T}$ cells in PBMCs from naïve and infected macaques at 2 weeks from infection. The number of samples analyzed varied from four to nine. (d-g) Mean percentages of CD4 ${ }^{+}$ $\mathrm{IL}-17^{+}$and CD4 ${ }^{+} \mathrm{IFN}-\gamma^{+}$T cells in pooled lymph nodes (d), jejunum (e), colon (f), and rectum (g) from naïve and infected macaques at 2 weeks from infection. The number of samples analyzed for each tissue varied from four to nine. IFN, interferon; IL, interleukin; PBMC, peripheral blood mononuclear cell; SIV, simian immunodeficiency virus; *MamuA-01+.

of Th17 cells is in agreement with other groups (G. Silvestri et al., personal communication) who have found unchanged numbers of Th17 cells in the non-pathogenic SIV model in sooty mangabeys. Because SIV infection of sooty mangabeys results in high level of viral replication, but no disease, the maintenance of normal numbers of Th17 cells may be key in preventing disease development. The definition of the full spectrum of activity of Th17 cells will help to further our understanding of AIDS pathogenesis and hopefully guide new therapeutic approaches.

\section{METHODS}

Animals. Colony-bred rhesus macaques (Macaca mulatta), obtained from Covance Research Products (Alice, TX), the University of Washington (Seattle, WA), and the Washington National Primate Research Center (Seattle, WA) were studied. All animals were housed and handled in accordance with the standards of the Association for the Assessment and Accreditation of Laboratory Animal Care International, and the National Institutes of Health guidelines. All studies were reviewed and approved by the animal care and use committees at Advanced BioScience Laboratories (ABL) (Kensington, MD). Of these animals, 13 were naïve, 9 were infected intrarectally with $\mathrm{SIV}_{\text {mac } 251}$ and sampled 2 weeks after infection (primary infection), and the remaining 18 were chronically infected with $\mathrm{SIV}_{\text {mac251 }}$ for 8 months or longer and had CD4 ${ }^{+} \mathrm{T}$-cell counts that ranged between 107 and 651 (Table 1) and virus plasma levels below (5 macaques) or above (13 macaques) 50 copies SIV RNA per $\mathrm{ml}$ of plasma. The chronically infected macaques had been infected 8 months or more at the time of euthanasia.

Viral load measurement. A real-time nucleic acid sequence-based amplification assay was used to measure SIV viral RNA in plasma. Plasma was clarified by centrifugation at $2,300 \mathrm{~g}$ for $3 \mathrm{~min}$. Clarified plasma $(0.1 \mathrm{ml})$ was lysed in $0.9 \mathrm{ml}$ lysis buffer. For samples expected to have low viral load, the clarified plasma $(0.5-1 \mathrm{ml})$ was centrifuged at $49,100 \mathrm{~g}$ for $60 \mathrm{~min}$. The virus pellet was then lysed in $1 \mathrm{ml}$ lysis buffer. Nucleic acid was isolated as described previously ${ }^{48}$ and then analyzed by real-time nucleic acid sequence-based amplification as described before. ${ }^{49}$ The real-time nucleic acid sequence-based amplification assay had a lower limit of sensitivity of 50 copies of RNA. 

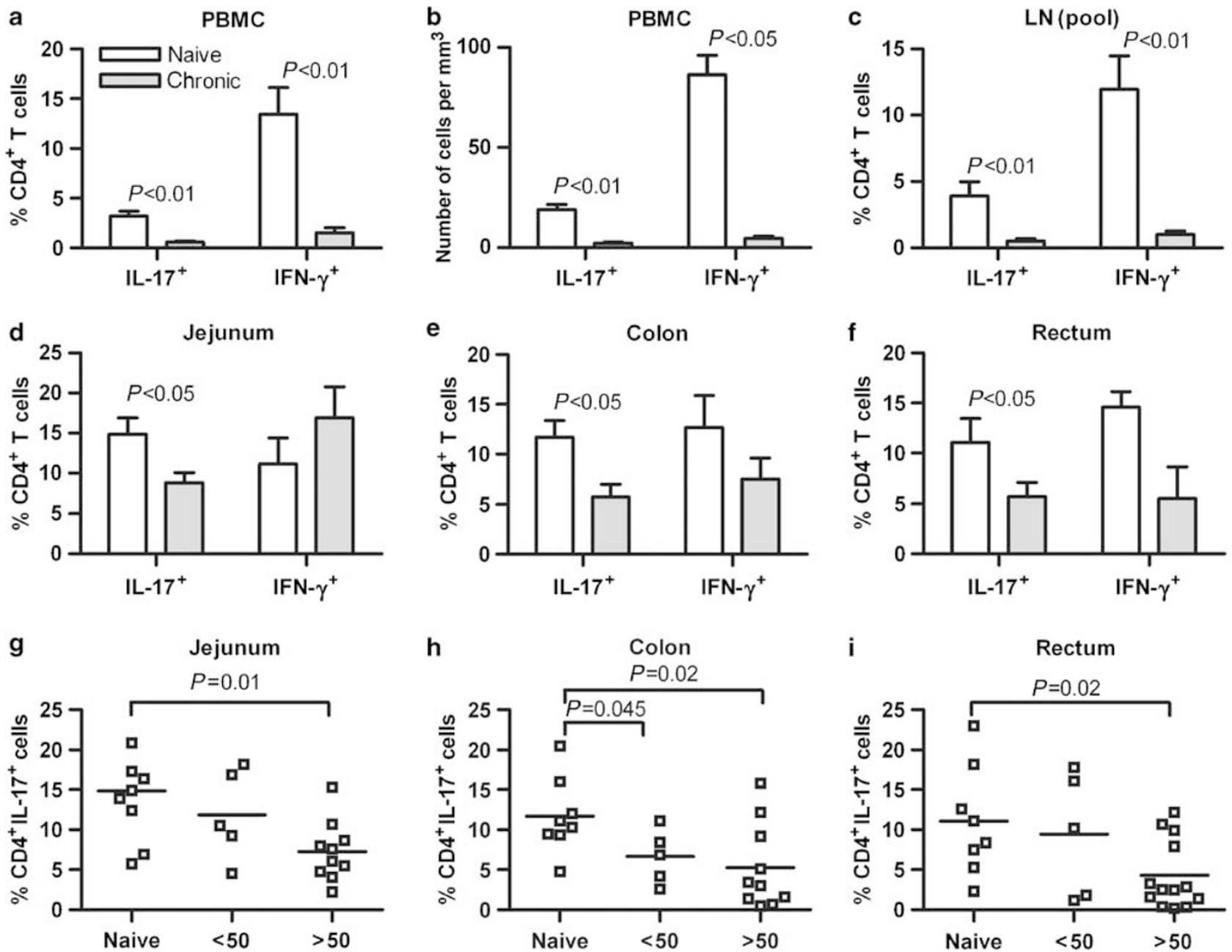

Figure 4 Frequency of Th17 and Th1 cells in chronically infected macaques. (a, b) Mean percentages (a) and absolute number (b) of CD4 ${ }^{+} \mathrm{IL}-17^{+}$and CD4 ${ }^{+}$IFN- $\gamma^{+}$T cells in PBMCs from naïve and chronically SIV-infected macaques. The number of samples analyzed varied from 4 to 11 . (c-f) Mean percentages of $\mathrm{CD} 4^{+} \mathrm{IL}-17^{+}$and $\mathrm{CD} 4^{+} \mathrm{IFN}-\gamma^{+}$T cells in pooled lymph nodes (c), jejunum (d), colon (e), and rectum (f) from naïve and chronically SIV-infected macaques. The number of samples analyzed for each tissue varied from 4 to 18 . (g-i) Mean percentages of $\mathrm{CD} 4^{+} \mathrm{IL}-17^{+} \mathrm{T}$ cells in jejunum (g), colon (h), and rectum (i) of naïve macaques and macaques with plasma virus levels below (elite controllers) or above 50 copies per ml. IFN, interferon; IL, interleukin; PBMC, peripheral blood mononuclear cell; SIV, simian immunodeficiency virus.

Preparation of lymphocytes from blood and tissues and in vitro

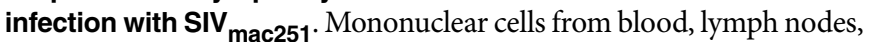
bronchoalveolar lavage, and spleen were isolated by density-gradient centrifugation on Ficoll and resuspended in RPMI 1640 medium (Gibco BRL, Gaithersburg, MD) containing 10\% fetal bovine serum and $1 \%$ penicillin-streptomycin (R-10). Tissues from jejunum, colon, and rectum were treated with $1 \mathrm{mM}$ of ultra pure dithiothreitol (Invitrogen, Carlsbad, CA) for $30 \mathrm{~min}$ followed by incubation in calcium/magnesiumfree Hank's buffered salt solution (Gibco BRL) 3-4 times for 60 min with stirring at room temperature to remove the epithelial layer. Lamina propria lymphocytes were separated following the removal of epithelium and intraepithelial lymphocytes. The remaining tissue was cut into small pieces and incubated with collagenase D $(400 \mathrm{U} / \mathrm{ml}$; Boehringer Mannheim, Mannheim, Germany) and DNase ( $1 \mu \mathrm{g} / \mathrm{ml}$; Invitrogen) for $2.5 \mathrm{~h}$ at $37^{\circ} \mathrm{C}$ in Iscove's modified Dulbecco's medium (Gibco BRL) supplemented with $10 \%$ fetal bovine serum and $1 \%$ penicillin-streptomycin. The dissociated mononuclear cells were than placed over $42 \%$ Percoll (General Electric Healthcare, Piscataway, NJ) and centrifuged at $800 \mathrm{~g}$ for $25 \mathrm{~min}$ at $4{ }^{\circ} \mathrm{C}$. Lamina propria lymphocytes were collected from the cell pellet.
Human $\mathrm{CD}^{+}{ }^{+} \mathrm{T}$ cells were sorted using the Miltenyi beads (Naïve $\mathrm{CD}^{+}{ }^{+}$T-Cell Isolation Kit; Miltenyi Biotec, Auburn, CA). SIV ${ }_{\operatorname{mac} 251}$ at a $4 \times 10^{3}$ TCID50 (50\% tissue culture infection dose) was incubated with $4-10 \times 10^{6}$ sorted $\mathrm{CD}^{+} \mathrm{T}$ cells for $4 \mathrm{~h}$; cells were washed and cultured in RPMI $10 \%$ fetal calf serum, supplemented with IL- 6 and IL- 1 . At 3 days following infection, the cell culture media were supplemented with $40 \mathrm{U} / \mathrm{ml}$ of recombinant IL-2. Infection was monitored by measuring p 27 in the supernatant of the cell culture using the Advanced BioScience Laboratories, ELISA kit (SIV p27 Antigen Capture Assay, catalog no. 5436).

LPS levels. Plasma samples were diluted fivefold with endotoxin-free water and then heated to $80^{\circ} \mathrm{C}$ for $10 \mathrm{~min}$ to inactivate plasma proteins. Plasma LPS was then quantified with a commercially available Limulus Amebocyte assay (Cambrex, Walkersville, MD) according to the manufacturer's protocol. Each sample was run in duplicate and background subtracted.

Intracellular cytokine staining for IL-17, cytokines, and viral antigens. Fresh or frozen lymphocytes were resuspended at $10^{6}$ per $\mathrm{ml}$ in R-10 

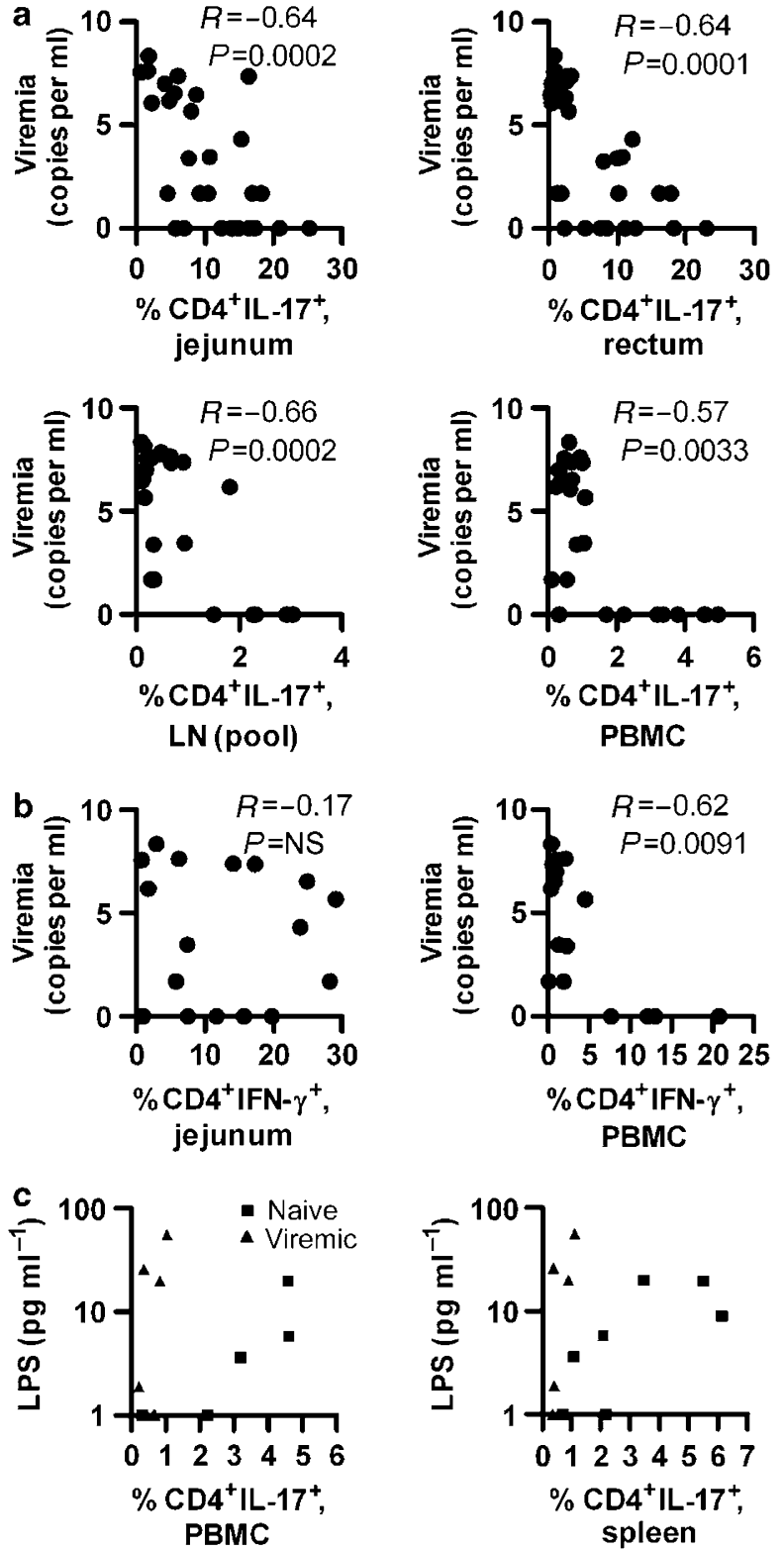

Figure 5 Correlative analysis of virus plasma levels and percentages of $\mathrm{CD} 4{ }^{+} \mathrm{IL}-17^{+} \mathrm{T}$ cells at mucosal sites or plasma LPS levels in infected macaques. (a) The frequency of Th17 cells in jejunum, rectum, pooled lymph nodes, and PBMCs was related to plasma virus levels (in log values) in the infected macaques. (b) The frequency of Th1 cells in jejunum and PBMCs was related to plasma virus levels (in log values) in the infected macaques. (c) The level of LPS in plasma was related to the frequency of Th17 cells in blood or spleen. No significant correlation was found in any tissue tested. IFN, interferon; IL, interleukin; LPS, lipopolysaccharide; PBMC, peripheral blood mononuclear cell.

supplemented with or without $50 \mathrm{ng} / \mathrm{ml}$ of PMA and $1 \mu \mathrm{g} / \mathrm{ml}$ of ionomycin (Sigma, St Louis, MO). After $1 \mathrm{~h}$ of incubation at $37^{\circ} \mathrm{C}$, concentrated monesin solution (eBioscience, San Diego, CA) was added to give a $1 \times$ concentration and cells were incubated for $4 \mathrm{~h}$ or more at $37^{\circ} \mathrm{C}$. Cells were then washed with $2 \%$ fetal bovine serum in phosphate-buffered saline (Gibco BRL) and surface stained with or without anti-human CD4 phycoerythrin (PE)/PerCP/allophycocyanin (APC), anti-human CD3 PerCP (Becton Dickinson Pharmingen, San Diego, CA), antihuman CD8 $\beta$ PE (Beckman Coulter, Fullerton, CA), anti-human CD8
PerCP (Becton Dickinson Pharmingen), and anti-human CD25 PE (Becton Dickinson Pharmingen). After $30 \mathrm{~min}$ of incubation in the dark at room temperature, cells were washed with cold $2 \%$ fetal bovine serum in phosphate-buffered saline. Cell pellets were resuspended with pulse vortex and $100 \mu \mathrm{l}$ IC Fixation Buffer (eBioscience) was added. Samples were incubated at $4^{\circ} \mathrm{C}$ for $20 \mathrm{~min}$ in the dark. After incubation, cells were washed twice with $2 \mathrm{ml} 1 \times$ Permeabilization Buffer (eBioscience) and centrifuged and decanted. Next, intracellular staining was performed in $100 \mu \mathrm{l}$ of $1 \times$ Permeabilization Buffer using anti-human IL-17 Alexa-Fluor488 (eBioscience) and anti-human IFN- $\gamma$ PE/APC (Becton Dickinson Pharmingen). After incubation for $30 \mathrm{~min}$ in the dark at room temperature, cells were washed twice with $2 \mathrm{ml} 1 \times$ Permeabilization Buffer.

Intracellular staining for viral antigens was performed using a mouse monoclonal anti-p27 antibody Advanced BioScience Laboratories. Briefly, after stimulation with PMA and ionomycin, cell pellets were fixed in $100 \mu$ IC Fixation Buffer (eBioscience). Intracellular staining was performed in $100 \mu \mathrm{l}$ of $1 \%$ rat serum in Permeabilization Buffer using a 1:10,000 dilution of the anti-p27 antibody. After incubation for $30 \mathrm{~min}$ in the dark at room temperature, cells were washed twice and stained with anti-mouse IgG1 Alexa-Fluor488 antibody (Invitrogen) for $30 \mathrm{~min}$ in the dark at room temperature. Next, cells were washed twice and stained using anti-human IL-17 APC (eBioscience) and anti-human IFN- $\gamma$ PE (R\&D Systems, Minneapolis, MN). After 30 min incubation in the dark at room temperature, cells were washed and resuspended in $1 \%$ paraformaldehyde (Electron Microscopy Sciences, Hatfield, PA) in phosphate-buffered saline. Four-parameter flow cytometry analysis was performed using CELLQuest software. List mode data files were analyzed using FlowJo software (Tree Star, Ashland, OR). In all cases at least 50,000 live events were collected for analysis.

Monoclonal antibodies and T-cell phenotyping. Monoclonal antibodies and dead cell dye used for phenotypic and functional characterization of T-cell subsets were anti-CD3 Cy7APC, anti-CD8 PB, anti-CD19 $\mathrm{PB}$, anti-CD14 PB, anti-IFN- $\gamma$ fluorescein isothiocyanate, anti-CD4 APC, anti-CD95 Cy5PE (Becton Dickinson Pharmingen), anti-CD28 Texas Red PE, anti-IL-17 PE (eBioscience), and violet-fluorescent reactive dye (Invitrogen). As naïe T cells do not produce either IL-17 or IFN- $\gamma$, memory, CD $4^{+} \mathrm{CD} 28^{+} \mathrm{CD} 95^{+} \mathrm{T}$ cells were separated based upon production of IL-17, IFN- $\gamma$, or neither.

Flow cytometric analysis. Four-parameter flow cytometric analysis was performed using a FACSCalibur flow cytometer (Becton Dickinson Immunocytometry Systems, San Jose, CA). Fluorescein isothiocyanate, PE, PerCP, and APC were used as the fluorophores.

Eighteen-parameter flow cytometric analysis was performed using a FACSAria flow cytometer (Becton Dickinson Immunocytometry Systems). Fluorescein isothiocyanate, PE, APC, Cy7APC, Texas Red $\mathrm{PE}$, violet amine reactive dye, and Pacific blue $(\mathrm{PB})$ were used as the fluorophores.

Quantitative PCR. Quantification of SIV Gag DNA in sorted memory CD4 T cells was performed by quantitative PCR by means of the $5^{\prime}$ nuclease (TaqMan) assay with an ABI7700 system (PerkinElmer, Norwalk, CT) as previously described. ${ }^{5}$ To quantify cell number in each reaction, quantitative PCR was performed simultaneously for albumin gene copy number as previously described. ${ }^{50}$ Standards were constructed for absolute quantification of Gag and albumin copy number.

Statistical analysis. The data presented in Figures 1e,f, $\mathbf{3 b}$-g, and 4a-i were analyzed using non-parametric Mann-Whitney $U$-test. The Spearman rank correlation method was used to analyze the data in Figure 5a-c.

\section{ACKNOWLEDGMENTS}

This research was supported by the Intramural Research Program of the NIH, National Cancer Institute, Center for Cancer Research. 
Thanks to W. Strober, Mucosal Immunity Section, Laboratory of Host Defenses, National Institute of Allergy and Infectious Diseases, for helpful discussion; L. Hudacik, D. Weiss, J. Treece, and R. Pal of Advanced BioScience Laboratories, for study assistance and animal care; and Steven Snodgrass for editorial assistance.

\section{DISCLOSURE}

The authors declared no conflict of interest.

(C) 2008 Society for Mucosal Immunology

\section{REFERENCES}

1. Giorgi, J.V. et al. Shorter survival in advanced human immunodeficiency virus type 1 infection is more closely associated with T lymphocyte activation than with plasma virus burden or virus chemokine coreceptor usage. J. Infect. Dis. 179, 859-870 (1999).

2. Hellerstein, M. et al. Directly measured kinetics of circulating $T$ lymphocytes in normal and HIV-1-infected humans. Nat. Med. 5, 83-89 (1999).

3. Grossman, Z., Meier-Schellersheim, M., Paul, W.E. \& Picker, L.J. Pathogenesis of HIV infection: what the virus spares is as important as what it destroys. Nat. Med. 12, 289-295 (2006).

4. Li, Q. et al. Peak SIV replication in resting memory CD4+ T cells depletes gut lamina propria CD4+ T cells. Nature 434, 1148-1152 (2005).

5. Mattapallil, J.J., Douek, D.C., Hill, B., Nishimura, Y., Martin, M. \& Roederer, M. Massive infection and loss of memory CD4+ T cells in multiple tissues during acute SIV infection. Nature 434, 1093-1097 (2005).

6. Mehandru, S. et al. Primary HIV-1 infection is associated with preferential depletion of CD4+ T lymphocytes from effector sites in the gastrointestinal tract. J. Exp. Med. 200, 761-770 (2004).

7. Veazey, R.S. et al. Gastrointestinal tract as a major site of CD4+ T cell depletion and viral replication in SIV infection. Science 280, 427-431 (1998).

8. Picker, L.J. et al. Insufficient production and tissue delivery of CD4+ memory $T$ cells in rapidly progressive simian immunodeficiency virus infection. J. Exp. Med. 200, 1299-1314 (2004).

9. Gordon, S.N. et al. Severe depletion of mucosal CD4+ T cells in AIDS-free simian immunodeficiency virus-infected sooty mangabeys. J. Immunol. 179, 3026-3034 (2007).

10. Milush, J.M. et al. Virally induced CD4+ T cell depletion is not sufficient to induce AIDS in a natural host. J. Immunol. 179, 3047-3056 (2007).

11. Abbas, A.K., Murphy, K.M. \& Sher, A. Functional diversity of helper T lymphocytes. Nature 383, 787-793 (1996).

12. Acosta-Rodriguez, E.V. et al. Surface phenotype and antigenic specificity of human interleukin 17-producing Thelper memory cells. Nat. Immunol. 8, 639-646 (2007)

13. Sher, A. \& Coffman, R.L. Regulation of immunity to parasites by T cells and T cell-derived cytokines. Annu. Rev. Immunol. 10, 385-409 (1992).

14. Ye, P. et al. Requirement of interleukin 17 receptor signaling for lung $C X C$ chemokine and granulocyte colony-stimulating factor expression, neutrophil recruitment, and host defense. J. Exp. Med. 194, 519-527 (2001).

15. Acosta-Rodriguez, E.V., Napolitani, G., Lanzavecchia, A. \& Sallusto, F. Interleukins 1 beta and 6 but not transforming growth factor-beta are essential for the differentiation of interleukin 17-producing human Thelper cells. Nat. Immunol. 8, 942-949 (2007).

16. Ivanov, I.I. et al. The orphan nuclear receptor RORgammat directs the differentiation program of proinflammatory IL-17+ Thelper cells. Cell 126, 1121-1133 (2006)

17. Nurieva, R. et al. Essential autocrine regulation by IL-21 in the generation of inflammatory T cells. Nature 448, 480-483 (2007).

18. Xu, L., Kitani, A., Fuss, I. \& Strober, W. Cutting edge: regulatory T cells induce CD4+CD25 - Foxp3 - T cells or are self-induced to become Th17 cells in the absence of exogenous TGF-beta. J. Immunol. 178, 6725-6729 (2007).

19. Zhou, L. et al. IL-6 programs $T(H)-17$ cell differentiation by promoting sequential engagement of the IL-21 and IL-23 pathways. Nat. Immunol. 8, 967-974 (2007)
20. Kolls, J.K. \& Linden, A. Interleukin-17 family members and inflammation. Immunity. 21, 467-476 (2004).

21. Happel, K.I. et al. Divergent roles of IL-23 and IL-12 in host defense against Klebsiella pneumoniae. J. Exp. Med. 202, 761-769 (2005)

22. Toy, D. et al. Cutting edge: interleukin 17 signals through a heteromeric receptor complex. J. Immunol. 177, 36-39 (2006).

23. Zheng, Y. et al. Interleukin-22, a T(H)17 cytokine, mediates IL-23-induced dermal inflammation and acanthosis. Nature 445, 648-651 (2007).

24. Liang, S.C. et al. Interleukin (IL)-22 and IL-17 are coexpressed by Th17 cells and cooperatively enhance expression of antimicrobial peptides. J. Exp. Med. 203, 2271-2279 (2006).

25. Duerr, R.H. et al. A genome-wide association study identifies IL23R as an inflammatory bowel disease gene. Science 314, 1461-1463 (2006).

26. Wilson, N.J. et al. Development, cytokine profile and function of human interleukin 17-producing helper T cells. Nat. Immunol. 8, 950-957 (2007).

27. Brenchley, J.M. et al. Microbial translocation is a cause of systemic immune activation in chronic HIV infection. Nat. Med. 12, 1365-1371 (2006).

28. Kotler, D.P., Reka, S. \& Clayton, F. Intestinal mucosal inflammation associated with human immunodeficiency virus infection. Dig. Dis. Sci. 38, 1119-1127 (1993).

29. Ullrich, R., Zeitz, M. \& Riecken, E.O. Enteric immunologic abnormalities in human immunodeficiency virus infection. Semin. Liver Dis. 12, 167-174 (1992).

30. Shevach, E.M. Regulatory T cells in autoimmunity*. Annu. Rev. Immunol. 18, 423-449 (2000).

31. Mangan, P.R. et al. Transforming growth factor-beta induces development of the $T(H) 17$ lineage. Nature 441, 231-234 (2006).

32. Bettelli, E. et al. Reciprocal developmental pathways for the generation of pathogenic effector TH17 and regulatory T cells. Nature 441, 235-238 (2006).

33. Veldhoen, M., Hocking, R.J., Atkins, C.J., Locksley, R.M. \& Stockinger, B. TGFbeta in the context of an inflammatory cytokine milieu supports de novo differentiation of IL-17-producing T cells. Immunity 24, 179-189 (2006).

34. Kinter, A.L. et al. CD25(+)CD4(+) regulatory T cells from the peripheral blood of asymptomatic HIV-infected individuals regulate CD4(+) and CD8(+) HIV-specific T cell immune responses in vitro and are associated with favorable clinical markers of disease status. J. Exp. Med. 200, 331-343 (2004).

35. Chase, A.J. et al. Severe depletion of CD4+CD25+ regulatory T cells from the intestinal lamina propria but not peripheral blood or Iymph nodes during acute SIV infection. J. Virol. 81, 12748-12757 (2007).

36. Boasso, A. et al. Do regulatory T-cells play a role in AIDS pathogenesis? AIDS Rev. 8, 141-147 (2006).

37. Wolk, K. et al. IL-22 induces lipopolysaccharide-binding protein in hepatocytes: a potential systemic role of IL-22 in Crohn's disease. J. Immunol. 178, 5973-5981 (2007).

38. Harrington, L.E. et al. Interleukin 17-producing CD4+ effector T cells develop via a lineage distinct from the Thelper type 1 and 2 lineages. Nat. Immunol. 6, 1123-1132 (2005).

39. Nesheim, S.R. et al. Trends in opportunistic infections in the pre- and post-highly active antiretroviral therapy eras among HIV-infected children in the Perinatal AIDS Collaborative Transmission Study, 1986-2004. Pediatrics 120, 100-109 (2007).

40. Kohli, R. et al. Bacterial pneumonia, HIV therapy, and disease progression among HIV-infected women in the HIV epidemiologic research (HER) study. Clin. Infect. Dis. 43, 90-98 (2006).

41. Sanchez, T.H. et al. Bacterial diarrhea in persons with HIV infection, United States, 1992-2002. Clin. Infect. Dis. 41, 1621-1627 (2005).

42. Wright, P. \& Inverarity, D. Human immunodeficiency virus (HIV) related cryptococcal meningitis in rural central Thailand-treatment difficulties and prevention strategies. Southeast Asian J. Trop. Med. Public Health 38, 58-61 (2007).

43. Kong, B.N. et al. Opportunistic infections and HIV clinical disease stage among patients presenting for care in Phnom Penh, Cambodia. Southeast Asian J. Trop. Med. Public Health 38, 62-68 (2007).

44. Micol, R. et al. Prevalence, determinants of positivity, and clinical utility of cryptococcal antigenemia in Cambodian HIV-infected patients. J. Acquir. Immune Defic. Syndr. 45, 555-559 (2007). 


\section{ARTICLES}

45. Horcajada, J.P. et al. [Specialized home care for infectious disease. Experience from 1995 to 2002.]. Enferm. Infecc. Microbiol. Clin. 25, 429-436 (2007)

46. Ranganathan, K., Magesh, K.T., Kumarasamy, N., Solomon, S., Viswanathan, R. \& Johnson, N.W. Greater severity and extent of periodontal breakdown in 136 south Indian human immunodeficiency virus seropositive patients than in normal controls: a comparative study using community periodontal index of treatment needs. Indian J. Dent. Res. 18, 55-59 (2007).

47. Khader, S.A. et al. IL-23 and IL-17 in the establishment of protective pulmonary $\mathrm{CD} 4+\mathrm{T}$ cell responses after vaccination and during
Mycobacterium tuberculosis challenge. Nat. Immunol. 8, 369-377 (2007).

48. Romano, J.W. et al. Quantitative evaluation of simian immunodeficiency virus infection using NASBA technology. J. Virol. Methods $\mathbf{8 6}$, 61-70 (2000).

49. Malkevitch, N.V. et al. Durable protection of rhesus macaques immunized with a replicating adenovirus-SIV multigene prime/protein boost vaccine regimen against a second SIVmac251 rectal challenge: role of SIV-specific CD8+ T cell responses. Virology 353, 83-98 (2006).

50. Douek, D.C. et al. HIV preferentially infects HIV-specific CD4+ T cells. Nature 417, 95-98 (2002). 